\title{
Uma prática docente inspirada na pedagogia freireana: a experiência na cátedra Paulo Freire da PUC-SP
}

\author{
SAUL, Ana Maria ${ }^{1}$ \\ SAUL, Alexandre ${ }^{2}$
}

\begin{abstract}
RESUMO
O texto apresenta o trabalho de docência desenvolvido na Cátedra Paulo Freire da PUC-SP, realizado no $1^{\circ}$ semestre de 2016, com 32 doutorandos e mestrandos. Essa experiência objetivou contribuir para o desenvolvimento profissional de educadores, alunos da Cátedra, nas dimensões de ensino e pesquisa, e concretizar princípios teórico-metodológicos da pedagogia freireana. A matéria-prima das aulas foram as preocupações e dúvidas que os educandos traziam em relação a possíveis conexões entre os objetos/problemas de pesquisa de suas Dissertações e Teses e a pedagogia de Paulo Freire, perpassadas pelos fatos e dados dos seus contextos de atuação profissional, e de suas percepções sobre eles. Um trabalho de leitura de realidade possibilitou levantar o universo temático do grupo-classe, dando origem a uma programação educativa dialógica, por meio da qual se pretendeu apreender criticamente o real, e a interdependência intrínseca entre os conteúdos estudados e a concretude dos problemas de pesquisa e das práticas pedagógicas dos estudantes. A Cátedra propôs-se a contribuir para a formação dos docentes-pesquisadores em uma vertente contra-hegemônica, opondo-se a processos formativos neotecnicistas de educação. Os principais resultados obtidos puderam ser evidenciados em produções de textos dos alunos, que demonstraram a apropriação de referenciais freireanos trabalhados no curso, a serem incorporados em suas Dissertações e Teses. A docência compartilhada por dois professores, na condução das aulas do semestre, constituiu-se em uma nova dimensão da docência que materializou saberes docentes e fundamentos da proposta da educação popular preconizada por Paulo Freire.
\end{abstract}

Palavras-chave: Paulo Freire. Prática docente. Cátedra Paulo Freire. Ensino superior.

Abstracto El artículo presenta el trabajo de docencia desarollado en la Cátedra Paulo Freire en la PUC-SP, que se ha realizado en el primero semestre de 2016, con 32 estudiantes de doctorado y de maestría. Esta experiencia tuvo como objetivo contribuir al desarrollo profesional de los educadores, alumnos de la "Cátedra", en las dimensiones de la enseñanza y de la investigación, y concretizar los principios teóricos y metodológicos de la pedagogía freireana. Un trabajo de lectura de la realidad

\footnotetext{
${ }^{1}$ Professora Titular do Programa de Estudos Pós-Graduados em Educação: Currículo da Pontifícia Universidade Católica de São Paulo (PUC-SP), Coordenadora da Cátedra Paulo Freire da PUC-SP. Email: anasaul@uol.com.br

2 Professor do Programa de Pós-Graduação Stricto Sensu em Educação da Universidade Católica de Santos (UniSantos), Coordenador da Cátedra Paulo Freire da UniSantos. E-mail: asaul@hotmail.com.br
} 
permitió levantar el universo temático del grupo-clase, lo que llevó a una programación educativa dialógica, a través de la cual se he pretendido captar críticamente el real, y la interdependencia intrínseca entre los contenidos estudiados y la materialidad de los problemas de investigación y de las prácticas pedagógicas de los estudiantes. Los principales resultados logrados pudieron ser evidenciados en las producciones de los textos de los alumnos que mostraron la apropiación de las referencias freireanas trabajadas en el curso, que serán incorporadas en sus disertación y tesis. Paulo Freire. Práctica docente. Cátedra Paulo Freire. Enseñanza superior

Paulo Freire. Práctica docente. Cátedra Paulo Freire. Enseñanza superior.

\section{Introdução}

O objetivo desse texto é apresentar e discutir o trabalho de docência que se desenvolve na Cátedra Paulo Freire da Pontifícia Universidade Católica de São Paulo, com a intenção de materializar princípios da pedagogia freireana ${ }^{3}$.

Paulo Freire foi professor da Pontifícia Universidade Católica de São Paulo (PUC-SP), pelo período de 17 anos (1980 -1997). Quando ele já não estava entre nós, no $2^{\circ}$ semestre de 1998, a Reitoria da PUC-SP aprovou a criação da Cátedra Paulo Freire, proposta pelo Programa de Estudos Pós-Graduados em Educação: Currículo.

A Cátedra Paulo Freire é um espaço especial para o desenvolvimento de estudos e pesquisas sobre, e a partir da obra de Paulo Freire. A Cátedra recebe, prioritariamente, mestrandos e doutorandos do Programa de Educação: Currículo.

No espaço da Cátedra os estudos visam a estudar criticamente o pensamento de Paulo Freire, para compreendê-lo e reinventá-lo. Busca-se atender à orientação e ao desejo de Freire, assim registrados desde o seu livro "Ação Cultural para a Liberdade", ao dizer sobre a continuidade de sua obra.

Quanto aos outros, os que põem em prática a minha prática, que se esforcem por recriá-la, repensando também meu pensamento. E ao fazê-lo, que tenham em mente que nenhuma prática educativa se dá

\footnotetext{
${ }^{3} \mathrm{O}$ uso deliberado do adjetivo freireano e flexões, assumido nesse texto e em produções da Cátedra Paulo Freire da PUC-SP, é uma questão de preferência, pela compreensão de que a manutenção da grafia integral do sobrenome do autor destaca com maior vigor a procedência das produções: a matriz de pensamento de Paulo Freire. Em alguns redutos acadêmicos significativos seguiu-se, pois, o seguinte critério: à ortografia original do antropônimo, foi acrescentado o sufixo ano, resultando no adjetivo freireano.
} 
no ar, mas num contexto concreto, histórico, social, cultural, econômico, político, não necessariamente idêntico. (FREIRE, 1981, p. 17).

Reinventar o legado freireano significa, na Cátedra Paulo Freire, fazer uma releitura crítica da obra do autor cuidando, no entanto, de não descaracterizar as suas propostas fundamentais, tendo em vista discuti-las frente aos novos desafios do mundo atual. E, sobretudo, construir e sistematizar uma práxis coerente com os princípios fundamentais da obra freireana. Rejeita-se, pois, qualquer compreensão de reinvenção que possa significar rompimento com o pensamento do autor para que se "faça tudo de novo". Ao mesmo tempo, entende-se como necessário, exercer uma postura crítica às ações que aproximam ou reduzem a filosofia e a pedagogia de Freire a métodos e técnicas, muitas dessas chanceladas por modismos e pela "grife" das chamadas inovações pedagógicas.

\section{A pedagogia de Paulo Freire: um quefazer na educação marcado por princípios da Educação Popular}

A luta intransigente de Paulo Freire contra situações de opressão e a favor de uma práxis democrática, sustentada por princípios de solidariedade e justiça social, definiram a sua compreensão e a sua prática a favor de uma Universidade progressista. Em seus escritos encontram-se princípios que podem ser tomados como crivo para orientar e, ou, analisar a práxis institucional de uma Universidade pautada pelo referencial da Educação Popular.

No conjunto desses princípios destaca-se o compromisso da Universidade a favor da construção de um conhecimento crítico-transformador, na direção de uma sociedade democrática, justa e solidária, que transborda e penetra a estrutura e o funcionamento de uma instituição de ensino superior.

Paulo Freire escreve:

Não se faz pesquisa, não se faz docência como não se faz extensão como se fossem práticas neutras. Preciso saber a favor de que e de quem, portanto contra que e contra quem pesquiso, ensino ou me envolvo em atividades mais além dos muros da Universidade. (FREIRE, 1993, p. 113). 
É possível dizer, a partir de escritos de Freire, que um trabalho, na Universidade, pautado pelos princípios da Educação Popular:

[...] jamais separa do ensino dos conteúdos o desvelamento da realidade.

[...] respeita os educandos, não importa qual seja sua posição de classe e, por isso mesmo, leva em consideração, seriamente, o seu saber de experiência feito, a partir do qual trabalha o conhecimento com rigor de aproximação aos objetos.

[...] trabalha, incansavelmente, a boa qualidade do ensino [...] através de rigoroso trabalho docente e não com frouxidão assistencialista.

[Está atento à necessária] formação científica e clareza política de que as educadoras e os educadores precisam para superar os desvios que, se não são experimentados pela maioria, se acham presentes em minoria significativa.

[...] em lugar de negar a importância da presença [...] da comunidade, dos movimentos populares na [instituição educacional] se aproxima dessas forças com as quais aprende para a elas poder ensinar também.

[...] supera os preconceitos de raça, de classe, de sexo e se radicaliza na defesa da substantividade democrática.

[...] não considera suficiente mudar apenas as relações entre [educadores] e educandos, amaciando essas relações, mas, ao criticar e tentar ir além das tradições autoritárias da escola velha, critica também a natureza autoritária e exploradora do capitalismo.

E ao realizar-se, assim, como prática eminentemente política, tão política quanto a que oculta, nem por isso transforma [a instituição] onde se processa em sindicato ou partido.

É que os conflitos sociais, o jogo de interesses, as contradições que se dão no corpo da sociedade se refletem necessariamente no espaço das [instituições educativas]. (FREIRE, 1993, p. 101-103).

Esses princípios exigem um quefazer político-pedagógico, no cotidiano da Universidade, a fim de que esta se concretize como uma instituição de ensino superior coerente com a Educação Popular defendida por Paulo Freire.

Não é suficiente, portanto, apenas declarar, embora absolutamente necessário, o compromisso de uma ação educativa, na Universidade, com o ideário da Educação Popular. A coerência dos princípios que definem esse compromisso precisa se expressar, também, nas ações de ensino, pesquisa e extensão. Cabe, em primeiro lugar, propor-se a superar certas dicotomias, por vezes frequentes.

Em "Pedagogia da Autonomia" Freire (1997) considera que ensino-pesquisa são ações que se interpenetram.

E, em "Pedagogia da Esperança" indaga: 
Como superar a tentação basista, voluntarista e, também a tentação intelectualista, verbalista, blablabante?

Como entender, mas sobretudo viver, a relação prática-teoria sem que a frase vire frase feita? (FREIRE, 1992, p.136).

Essas questões requerem reflexão contínua, pois elas pervadem as diferentes esferas de ação da Universidade. Não se trata de respostas fáceis, rápidas, porque essas não são perguntas retóricas. É preciso construir tais respostas em diálogo aprofundado que passa pela prática e pela teoria, sempre, no cotidiano demandante das instituições de ensino.

Aos professores cabem, continuamente, decisões que estão no coração de suas práticas e que respondem às perguntas: Que conteúdo ensinar? Como ensinar? Como avaliar?

Vale resgatar, aqui, as questões que nos faz Paulo Freire, em "Pedagogia da Esperança", no tocante a uma Universidade que se quer encharcada dos princípios da Educação Popular:

Que conteúdos ensinar, a favor de que ensiná-los, a favor de quem, contra que, contra quem. Quem escolhe os conteúdos e como são ensinados?

Que é ensinar? Que é aprender? Como se dão as relações entre ensinar e aprender? Que é o saber de experiência feito? Podemos descartá-lo como impreciso desarticulado? Como superá-lo?

Que é o professor? Qual seu papel? E o aluno, quem é? E o seu papel? Não ser igual ao aluno significa dever ser o professor autoritário? É possível ser democrático e dialógico sem deixar de ser professor, diferente do aluno? Significa o diálogo um bate-papo inconsequente cuja atmosfera ideal seria a do "deixa como está para ver como fica"?

Pode haver uma séria tentativa de escrita e leitura da palavra sem a leitura do mundo?

Significa a crítica necessária à educação bancária que o educador que a faz não tem o que ensinar e não deve fazê-lo? Será possível um professor que não ensina? Que é a codificação, qual o seu papel no quadro de uma teoria do conhecimento? (FREIRE, 1992, p.135).

Novamente, vale insistir, essas não são questões retóricas. Debruçar-se sobre as mesmas, para respondê-las e para construir uma prática coerente, implica adentrar questões políticas, que se referem à utopia de uma sociedade democrática, justa e solidária. Em decorrência, cabe questionar a natureza do conhecimento que é 
construído/distribuído na Universidade e que, não pode ser outro, senão um conhecimento crítico-transformador.

Na vertente das questões epistemológicas, cabe discutir qual é o conhecimento crítico/significativo a ser trabalhado na Universidade. E aqui, a questão do senso comum, entendido como saber de experiência feito, tem se constituído em um divisor de águas, em confronto com o dito saber construído historicamente pela humanidade. Não tem sido reconhecida, por educadores alinhados com a educação bancária, a necessidade de valorizar e equacionar essas diferentes produções, todas elas construídas, em tempos históricos, pela humanidade.

As questões pedagógicas dizem da docência-discência e da avaliação. Um primeiro saber a compreender, sublinhado por Paulo Freire, é: quem ensina aprende e quem aprende, ensina. A partir desse entendimento, o diálogo assume uma categoria central como forma de construção de conhecimento, na relação ensinoaprendizagem. Destaque-se, aqui, a imprescindível leitura crítica da realidade que inclui a necessidade de partir do conhecimento dos educandos, e não ficar nele, para a construção do conhecimento crítico. Integrando essa discussão, coloca-se a urgência de superar os condicionamentos de um saber-fazer disciplinar, fragmentado, na direção de um conhecimento inter/trans/multidisciplinar. E, finalmente, não com menor importância, vem à pauta a questão da avaliação, em suas diferentes modalidades, desde a chamada avaliação dos educandos ou avaliação da aprendizagem, passando pela avaliação de cursos, projetos e avaliação institucional, propriamente dita. Em todos esses âmbitos da avaliação educacional na instituição universitária, é fundamental que se considere que a avaliação não pode ser entendida como controle, desenvolvida com práticas autoritárias e ameaçadoras. A avaliação que importa, em uma perspectiva de Educação Popular, é aquela que serve a propósitos emancipatórios, contribuindo para a qualidade social da educação.

É importante que se diga que uma Universidade que objetiva ter uma proposta e uma prática pautadas nesses princípios da Educação Popular precisará ter vontade política, disposição e ações para questionar e mudar paradigmas estabelecidos que, muitas vezes estão em direção oposta a essa, por conta de opções ideológicas dos educadores, respectivas histórias de vida, formação e hábitos. Essa não é uma tarefa fácil. Diz Freire: "[...] a Educação Popular cuja posta em prática, em termos amplos, 
profundos e radicais numa sociedade de classe, se constitui como um nadar contra a correnteza" (FREIRE,1993). Porém, vem dele mesmo a esperança e o apelo, em epígrafe de seu livro "A Educação na Cidade" (1991): "Mudar é difícil, mas é possível e urgente".

Tem-se buscado, na Cátedra Paulo Freire, estimular o desenvolvimento acadêmico dos participantes, subsidiando seus quefazeres pedagógicos e pesquisas com aportes teóricos significativos, ou seja, com teorias que se colocam a serviço do descortinamento e superação das contradições sociais, tendo como referência as necessidades apontadas pelos sujeitos da prática educativa. Nas aulas são criadas oportunidades para que os discentes possam dizer a sua palavra e dialogar com os colegas e professores, para avançar na compreensão dos principais problemas que os impedem de ser mais.

\section{Metodologia}

A matéria-prima das aulas semanais, que tiveram início em fevereiro de 2016, e se encerraram em meados de junho, foram as preocupações e dúvidas que os educandos ${ }^{4}$ traziam em relação a possíveis conexões entre os objetos/problemas de pesquisa de suas Dissertações e Teses e a pedagogia de Paulo Freire, perpassadas pelos fatos e dados dos seus contextos de atuação profissional, e de suas percepções sobre eles. Um trabalho de leitura de realidade (FREIRE, 1987) possibilitou levantar os temas de interesse do grupo-classe, dando origem a uma programação educativa dialógica, por meio da qual aprofundou-se o estudo dos temas e conceitos da pedagogia freireana, com a intenção de subsidiar os pós-graduandos em suas pesquisas e práticas pedagógicas.

O planejamento das aulas, realizado pelos dois professores da Cátedra Paulo Freire $^{5}$, em uma perspectiva colaborativa ${ }^{6}$, era construído semanalmente e levava em

\footnotetext{
4 Mestrandos e Doutorandos alunos de diferentes cursos de Pós-Graduação da PUC-SP (Educação: Currículo, Educação: Formação de Formadores, Educação: Psicologia da Educação e do Programa de Pós-Graduação em Filosofia da PUC-SP).

${ }^{5}$ No primeiro semestre de 2016, trabalharam como docentes da Cátedra Paulo Freire da PUC-SP a profa. Ana Maria Saul e o prof. Alexandre Saul.

${ }^{6}$ Conferir o conceito de colaboração em Freire (1987), Imbernón (2004) e Fiorentini (2013).
} 
consideração as propostas dos docentes em relação ao estudo sistemático, rigoroso e intencional do pensamento de Freire, e as necessidades apresentadas pelos alunos a cada aula. Essa opção exigiu dos professores disposição para aprender um com o outro e com o grupo de estudantes, abertura ao diálogo e capacidade de escuta. Requereu, também, condições objetivas que permitiram aos docentes da Cátedra tempo para estudo e elaboração conjunta do quefazer educativo.

$\mathrm{Na}$ sala de aula, as cadeiras eram sempre dispostas em círculo, seguindo a tradição do trabalho educativo desenvolvido por Paulo Freire, nos "Círculos de Cultura"7.

No início de cada aula, a proposta de trabalho era apresentada e discutida com a turma, podendo ser alterada e acrescida a partir de comentários dos alunos. Em seguida, sempre havia um primeiro momento de diálogo sobre os acontecimentos da semana que, sob ótica dos pós-graduandos e dos professores, eram considerados importantes para discutir no coletivo da Cátedra. Dentre os temas debatidos, merecem destaque questões ligadas à política mais ampla, como o impeachment da presidenta Dilma, noticiado pela imprensa, questões ligadas à política educacional, como os projetos de lei que pretendem instituir as "Escolas sem Partido", e outros assuntos relacionados à política universitária, além de medos e angústias advindas das práticas dos participantes, em seus contextos profissionais. Buscou-se, assim, jamais deixar de lado a preocupação em desvelar as interconexões entre os contextos concretos dos participantes da e o contexto teórico da Cátedra (FREIRE, 1995). Segundo Freire,

O professor se faz educador autêntico na medida em que é fiel a seu tempo e a seu espaço. Sem esta fidelidade, mesmo bem intencionado, se compromete sua atividade formadora. É que não pode haver formação do educando se o conteúdo da formação não se identifica com o clima geral do contexto a que se aplica. Seria antes uma deformação (FREIRE, 1962, p.46).

\footnotetext{
${ }^{7}$ As razões para a disposição das cadeiras em círculo foram discutidas com os alunos desde a primeira aula. Aos poucos, os estudantes foram assumindo essa forma de trabalho como um valor para si, conectado a uma prática educativa democrática e dialógica, passando a chegar mais cedo para arrumar as cadeiras na posição adequada antes da chegada dos professores. Sobre o trabalho nos "Círculos de Cultura" conferir (FREIRE, 1987, 1981).
} 
$\mathrm{Na}$ primeira aula foi apresentado e discutido o cronograma do curso e a proposta de trabalho para o semestre. Para levantar os temas de interesse dos alunos foram feitas a eles, por escrito, as seguintes questões:

1) Qual é o seu problema de pesquisa?

2) O que você busca na Cátedra Paulo Freire, diante do seu problema de pesquisa?

As respostas lidas e comentadas por seus respectivos autores, foram também entregues aos professores. Uma análise do material escrito, enriquecido por anotações provenientes da aula, permitiu aos docentes da Cátedra caracterizar um universo temático do grupo-classe, relacionado ao pensamento de Freire. Diante da impossibilidade de trabalhar, com profundidade, em um único semestre, com um grande volume de conceitos, alguns deles foram priorizados. Dentre os conceitos presentes nas respostas dos alunos, de forma explícita e implícita, aqueles que apareceram com maior frequência e apresentaram maior aderência ao critério de pertinência à obra de Freire, foram: educação problematizadora, leitura do mundo, humanização/transformação/justiça social, diálogo, currículo e prática pedagógica.

A organização do estudo sistemático dos conceitos selecionados foi pensada a partir de uma trama conceitual freireana (SAUL, A. M.; SAUL, A., 2013), construída pelos professores e debatida com o grupo, cujo centro foi a educação problematizadora, ou seja, o conceito que mais despertava a curiosidade e a preocupação dos educandos. Com a trama, foi possível estudar cada um dos conceitos de forma relacional, isto é, possibilitando que a compreensão inicial que se pode ter sobre ele fosse enriquecida e ampliada em um processo de cisão e retotalização do mesmo, que resulta em um conhecimento mais denso e complexo do conceito. Respeitou-se, também, o caráter relacional da obra de Freire e a proposta desse autor de que o ato gnosiológico não prescinda de um "cerco epistemológico", isto é, da compreensão das inter-relações e múltiplas determinações que se estabelecem entre os objetos de conhecimento (FREIRE, 1995).

A representação gráfica da trama conceitual elaborada para compreender, analisar e trabalhar com o conceito de educação problematizadora, ao longo do 
primeiro semestre letivo de 2016, na Cátedra Paulo Freire, é apresentada na figura a seguir.

Figura 1 - Uma trama conceitual freireana centrada na educação problematizadora

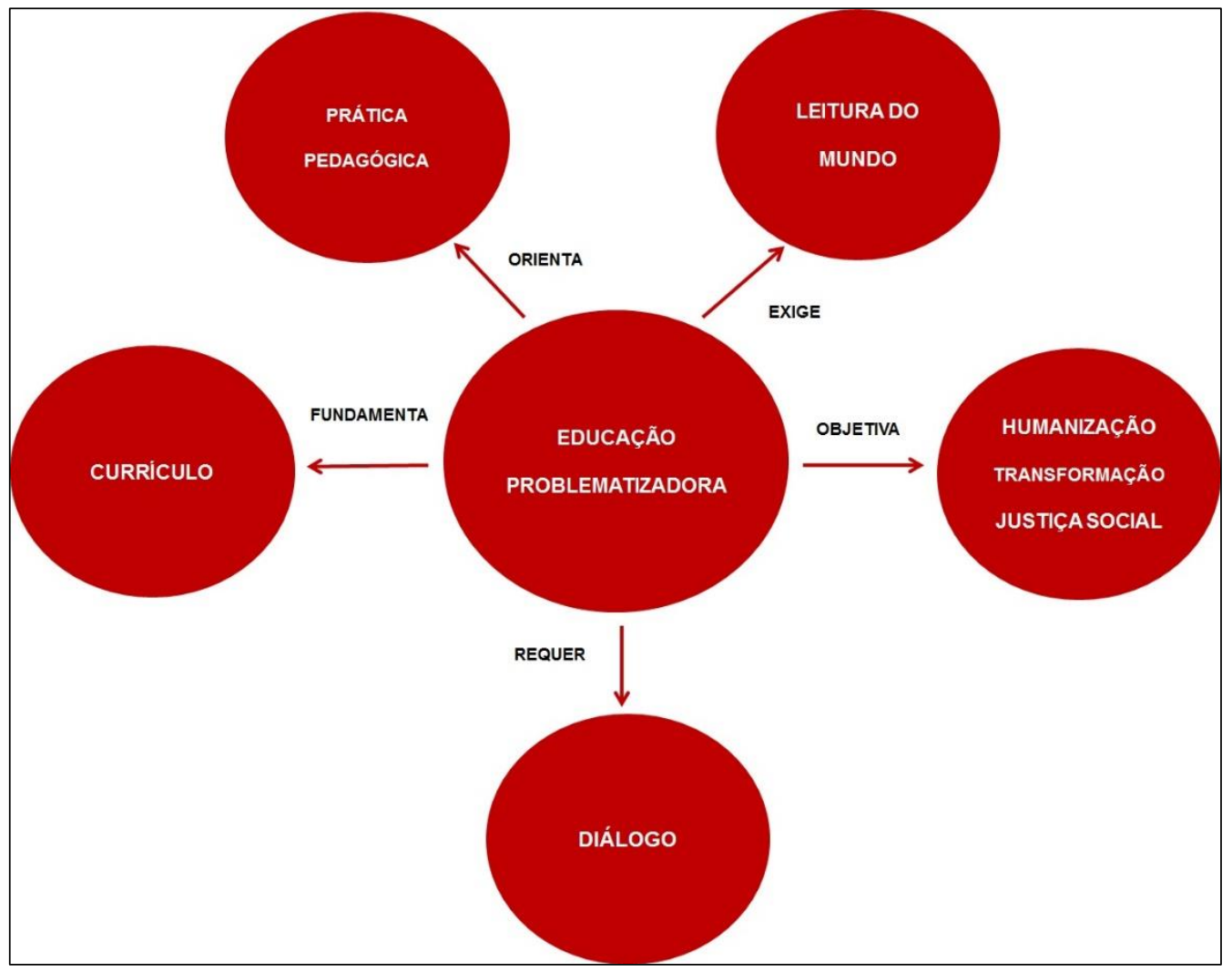

Fonte: Autores

Passou-se então a estudar cada um dos conceitos com a utilização de diferentes estratégias formativas e dinâmicas que incluíram:

1. Levantamento de saberes de experiência dos participantes, por meio de problematizações que buscavam fazer emergir conhecimentos advindos de suas práticas e de dados da realidade em relação à temática estudada.

2. Diálogo em pequenos e grandes grupos a partir de excertos de textos, trechos de vídeos e textos completos, indicados para estudo pelos professores da Cátedra. São exemplos dos textos indicados: "Cinco razões para dialogar com Paulo Freire", de Danilo Streck; "Mudar é difícil mas é necessário e urgente: um novo sentido para o projeto político pedagógico da escola”, de Ana Maria Saul e Alexandre Saul; "O que é o método dialógico de ensino? O que uma pedagogia "situada" e o 
empowerment? - Capítulo 4 do livro "Medo e ousadia: o cotidiano do professor", de Paulo Freire e Ira Shor; "Papel da educação na humanização", de Paulo Freire; Capítulo 2 do livro "Pedagogia do Oprimido", de Paulo Freire; Capítulo 1 do livro "Pedagogia da Autonomia", de Paulo Freire; "Formação de professores em Paulo Freire: uma filosofia como jeito de ser-estar e fazer pedagógicos ", de Eliete Santiago e José Batista Neto; e outros.

3. Análise coletiva e relacional de tramas conceituais, produzidas pelos estudantes, tendo como centro o conceito principal a ser trabalhado em suas Dissertações ou Teses, permitindo a composição de sínteses coletivas sobre um determinado conceito e outros, a ele relacionados.

4. Realização de jogos teatrais que permitiram aos participantes construir um clima favorável ao desenvolvimento do trabalho de formação de pesquisadoresdocentes, exigindo cooperação, concentração, descontração e confiança.

5. Apresentação de pesquisas de egressos da Cátedra Paulo Freire que guardavam relação com os conceitos estudados.

6. Participação de professores de outras Universidades e/ou Programas de Pos-Graduação para aprofundamento teórico-metodológico. Como foi o caso das aulas ministradas pelo prof. Dr. Dario Fiorentini, da Unicamp, e pela profa. Dra. Bernardete Gatti, da Fundação Carlos Chagas.

7. Elaboração de textos que descrevessem uma prática educativa ou intenções de pesquisa dos alunos, com o objetivo de realizar análises coletivas das mesmas, tendo como crivo crítico a trama conceitual com centro na educação problematizadora, construída e estudada na Cátedra.

\section{As produções dos alunos: uma avaliação crítico-reflexiva do curso}

No final do semestre letivo, solicitou-se aos alunos que expressem as suas compreensões do que foi vivenciado na disciplina, em produções escritas. Esse foi o momento de sistematizar, de forma sintetizada, a produção de conhecimento que os participantes da Cátedra tiveram durante o curso.

Em seus textos, os pós-graduandos deveriam apresentar reflexões, explicitar e justificar formas ou perspectivas de utilização/articulação dos conceitos freireanos 
analisados nas aulas, nas práticas e/ou pesquisas relatadas/anunciadas nos textos, tendo em vista melhor compreender suas realidades profissionais, suas indagações de pesquisa, ou, ainda, analisar resultados obtidos em investigações. Para confecção dos manuscritos, foi sugerido que os alunos revisitassem os textos indicados/lidos durante o curso e também consultassem outros. Algumas dessas produções foram apresentadas e discutidas nas aulas, e todas foram entregues aos professores da Cátedra, como parte da avaliação final do curso.

Objetivou-se que esse momento fosse caracterizado como uma avaliação crítico-reflexiva sobre o trabalho desenvolvido, tomando-se como referência as expectativas iniciais dos mestrandos e doutorandos e o percurso trilhado durante 0 semestre. Alguns alunos escreveram sobre a contribuição das aulas para as suas Dissertações e Teses, quer do ponto de vista da fundamentação teórica, quer do ponto de vista metodológico. O trabalho sobre tramas conceituais freireanas chamou muito a atenção do grupo-classe e, em virtude desse fato, várias tramas conceituais foram construídas, de acordo com o interesse dos pesquisadores desse grupo. Outras produções foram apresentadas demonstrando a contribuição do curso para as práticas dos alunos, na docência, na gestão de escolas ou em outras instâncias da educação. As produções escritas foram discutidas nas aulas, como mais um momento da trajetória de formação de alunos e professores.

As análises das sistematizações constituíram momentos valiosos de avaliação formativa, conquanto geraram novas produções de conhecimento e indicações importantes para os próximos semestres de trabalho da Cátedra Paulo Freire. Ao mesmo tempo, foram momentos prazerosos porque o grupo desenvolveu relações de respeito, e e confiança que permitiram uma convivialidade amorosa e solidária.

\section{Considerações finais}

A experiência de docência aqui relatada atestou a possibilidade e o valor de se trabalhar com princípios da pedagogia freireana no ensino superior e, em especial, na Pós-Graduação. Assumindo o compromisso ético-político de desenvolver a docência a partir da problemática de pesquisa e dos interesses dos educandos, como ponto de partida do processo crítico de construção de conhecimentos, a Cátedra propôs-se a 
contribuir para a formação de pesquisadores em uma vertente contra hegemônica, porque defende uma proposta que se opõe a processos formativos prescritivos, reprodutivistas e conteudistas de educação.

Destaque-se, também, que essa experiência, aqui relatada, pôde consolidar uma proposta de docência compartilhada com dois professores que trabalharam em uma perspectiva colaborativa, nos momentos de planejamento e em cada aula, semanalmente. Ao analisar, com os alunos, a prática de docência compartilhada dos professores que conduziram o trabalho nesse semestre, foi possível percorrer muitos dos 27 saberes docentes apresentados por Paulo Freire em "Pedagogia da Autonomia - saberes necessários à prática docente". Constatou-se que o diálogo, o respeito, a autonomia partilhada, a interdisciplinaridade, a humildade, os saberes de experiência feito, dentre outros, são saberes que foram se tramando, necessariamente, na construção dessa proposta de docência experienciada na Cátedra Paulo Freire da PUC-SP, nesse primeiro semestre de 2016.

\section{Referências}

FIORENTINI, Dario. Pesquisar práticas colaborativas ou pesquisar colaborativamente? In: BORBA, Marcelo de Carvalho; ARAÚJO, Jussara de Loiola (Orgs.). Pesquisa qualitativa em educação matemática. Belo Horizonte: Editora Autêntica, 2013. p. 53-86.

FREIRE, Paulo. A educação na cidade. São Paulo: Editora Cortez, 1991.

À sombra desta mangueira. São Paulo: Editora Olho D’água, 1995. Terra, 1981.

Ação cultural para a liberdade e outros escritos. Rio de Janeiro: Paz e . Cartas à Guiné-Bissau - registros de uma experiência em processo. São Paulo: Paz e Terra, 1977.

O professor universitário como educador. Estudos Universitários: Revista de Cultura da Universidade do Recife, Recife: Imprensa Universitária, v. 1, 1962.

Pedagogia da autonomia: saberes necessários à prática educativa. Rio de Janeiro: Paz e Terra, 1997. 
Pedagogia da esperança: um reencontro com a Pedagogia do oprimido. Rio de Janeiro: Editora Paz e Terra, 1992.

Pedagogia do oprimido. Rio de Janeiro: Paz e Terra, 1987.

Política e educação. São Paulo: Editora Cortez, 1993.

IMBERNÓN, Francisco. Formação docente e profissional: formar-se para a mudança e a incerteza. Questões da nossa época. São Paulo: Editora Cortez, 2004.

SAUL, Ana Maria; SAUL, Alexandre. Mudar é difícil mas é necessário e urgente: um novo sentido para o projeto político pedagógico da escola. Revista Teias, v.14, n. 33, p.102-120. Dossiê Especial, 2013. 